\section{And now some good news}

\section{Paris}

After 11 months of calculation and rethinking, scientists at the European Space Agency (ESA) now believe that the seemingly ill-fated astronometry satellite, Hipparcos, will be able to perform its mission successfully after all. A request for ESA to build a follow-up, Hipparcos 2, has been dropped.

Hipparcos was launched last August by an Ariane rocket with the intention of gathering information on the position, proper motion and distance of 120,000 stars to a new order of precision. The launch itself was perfect - but then the apogee boost-motor failed, leaving the satellite in a highly elliptical orbit, rather than the geostationary orbit that was originally planned (see Nature 340, 581; 1989). The load thus put on the satellite's three solar arrays seemed likely to limit the mission to a duration of six months, rather than the planned four years. Data collection also became a problem as the elliptical orbit put the satellite out of reach of a single tracking station and transmissions were regularly obscured as the satellite passed through the Van Allen belts.

Since then, help to track Hipparcos has been found at ground stations in Perth (Australia), Kourou (French Guiana) and Goldstone (United States), adding to the planned activities at Odenwald in West Germany. That means that the satellite is visible 93 per cent of the time and useful observations can be made 60 to 70 per cent of the time.

The future of the mission depends on the rate at which voltages from the solar panels decline. Mike Perryman, Hipparcos project scientist at ESA, last week said that projections based on rates collected over several months suggest Hipparcos may last two to three years "or four or even longer". That will allow the 120,000 stars of the input catalogue to be positioned with 10-20 milliarc accuracy, still, according to Perryman, 10-20 times better than could be achieved from the ground.

For Perryman, the effect of the failure is now on the quantity of observations, not their quality. "We cannot retrieve quite as much data, but for the 70 per cent of the time when we do get data, the quality is outstanding. We are delighted." Over 5 million observations have already been made of the 120,000 stars.

An 11-man enquiry board set up to investigate the failure of Hipparcos submitted its final report and recommendations last week. French defence department missile expert Daniel Reydellet, who chaired the inquiry board, said in Paris that an 'off-the- shelf' component in the ignition circuit of the apogee booster motor - the through bulkhead initiator (TBI) - apparently did not work. But Reydellet was reluctant to say whether the TBI, made by the California-based company, Hi Shear, was faulty. The TBI depends for correct functioning on pulses from other parts of the ignition circuitry.

The report neverthless suggests that $\mathrm{Hi}$ Shear's reputation with the US National Aeronautics and Space Administration may have dazzled ESA engineers into foregoing quality control checks. When, as part of the inquiry, experts visited $\mathrm{Hi}$ Shear, Reynellet said they found that

\section{EUROPEAN SPACE PROGRAMME}

\section{Munich}

A sMOUldering dispute over the West German space programme flared into life again last week when the 1991 budget of the West German Research Ministry (BMFT) was announced. Space research and technology accounted for half of the 4 per cent increase in the budget, prompting renewed criticism from the opposition parties that BMFT was taking money away from other areas by investing so much in manned space flight.

With the estimated cost of the European space station Columbus, which is supposed to complement the US space station Freedom, having risen by thousands of millions of dollars, West Germany has found its role as main developer of Columbus, bearing 38 per cent of the cost, increasingly difficult to shoulder. When the European Space Agency (ESA) council decided in 1987 to begin three linked space projects - Columbus, the space shuttle Hermes and a heavy payload rocket Ariane-5 - the total cost was estimated at DM 21,000 million $(\$ 12,800$ million).

Since then, the price has risen to an estimated minimum of DM 30,000 million, according to opposition members of the West German parliament. BMFT refused to confirm any such figure, but admitted that large increases would be necessary in 1992 and beyond to cover the rising cost of the programme. West German Research Minister, Heinz Riesenhuber (Christian Democrat), has promised not to let space research take more than 22 per cent of BMFT's budget. That proportion is now 20 per cent.

Columbus is meant to be both a vehicle for basic research in microgravitation and a platform for industrial research and development, but critics claim that neither goal will be met by the current plan. Opposition Social Democratic parliamentarian Edelgard Bulmahn doubts that the latest US plan for space station Freedom
TBIs originating from the same batch as the one used in Hipparcos had "disappeared", thereby ruling out fresh tests. Because the components can be used only once, statistics from the testing of a whole batch are needed to assess reliability. Neverthless, analyses being carried out by ESA have suggested that quantities of explosive may have been only just within the required specifications.

Wise after the event, the inquiry board has recommended that, when off-theshelf components are bought in future, ESA engineers should monitor manufacture more closely. But, given the complexity of modern satellites, this may not be realistic.

\title{
Columbus shipwrecked?
}

- to use it as a stopping-place for missions to the Moon and Mars - is compatible with using Columbus for microgravity research.

Anticipating a major budget battle, BMFT requested as early as 1987 that ESA cut its budget for the three projects by 15 to 20 per cent. But Buhlman says that cuts of this size would reduce the amount of new technology that European countries could develop, forcing ESA to buy much of the needed technology from the United States.

The members of Helmut Kohl's centreright coalition gave a vote of confidence to Columbus last month before parliament adjourned for the summer. But the support may be conditional. Christian Democrat parliamentarian Christian Lenzer says he is "totally against building something that industry is not interested in using," sowing the seeds for a conflict with BMFT, which defends the project as an important investment in basic research. And a spokeswoman for the prime contractor for Columbus, MBB-ERNO in Bremen, said that "it will take 15 years" before the space station "becomes a business" the way that satellites or launch vehicles have.

Adding to the confusion, an ESA review board gave the MBB-ERNO proposal a low rating; the proposal was judged to be "of a generally low level of quality", and the "quality and accuracy of the cost data" was declared "totally unacceptable, with an extremely low level of credibility". An ESA spokesman said it was normal for a large proposal to receive a negative evaluation early in the approval process.

Next year, ESA member states will meet to decide how to proceed with the three space projects. If costs rise more than 20 per cent from original estimates, member states have the option to withdraw from the programme.

Steven Dickman 